\title{
DE SÃO PAULO À PORTO ALEGRE: REFLEXIVIVENCIANDO A TROCA DE EXPERIÊNCIAS ENTRE PIBID E ESTÁGIOS DE LICENCIATURA NA BUSCA DA FORMAÇÃO DE BONS PROFESSORES
}

\author{
From São Paulo to Porto Alegre: reflecting the exchange of experiences between PIBID and \\ teacher education programs in search of the training of good teachers
}

Nestor André Kaecher* Jorge Luiz Barcellos da Silva**

* Professor do PPG em Geografia - UFRGS - nestorandrek@gmail.com.

**Professor da UNIFESP - Guarulhos - jorge.barcellos@unifesp.br.

\begin{abstract}
Resumo:
Qual o sentido de formar professores para a Educação Básica? Qual o sentido de ser professor na Educação Básica? Como pensar a construção da identidade do professor? São algumas questões que os autores - um em Guarulhos, SP (UNIFESP) formando pedagogas e o outro envolvido com a Licenciatura Noturna de Geografia, em Porto Alegre, RS (UFRGS) - pretendem reflexionar. Sem a pretensão de propor respostas 'essencialistas'. A partir da experiência com o PIBID na UNIFESP e com os estágios finais de licenciatura na UFRGS, apontamos um pouco da trajetória dos alunos, no processo de sua formação. A busca de positividades e de fraquezas em ambas as experiências aponta-nos para a busca do professor reflexivo, aquele cuja ação evita ser repetitiva e acomodada.
\end{abstract}

Palavras-chave: Formação de professores; Professor reflexivo.

\begin{abstract}
:
What is the meaning of training teachers for Basic Education? What is the meaning of being a Basic Education teacher? How to think about developing the teacher's identity? These are some of the issues that the authors one in Guarulhos, SP (UNIFESP) educating pedagogues and the other involved with the Geography Teaching Education Night Course, in Porto Alegre, RS (UFRGS) - intend to reflect upon. Not pretending to propose 'essentialist' answers. Based on the experience with the PIBIB at UNIFESP and the final stages of the teacher education course at UFRGS, we observe some of the students' journey, in the process of their development. The search for positivities and weaknesses in both experiences points us to the search for the reflexive teacher, the one whose action avoids being repetitive and accommodated.
\end{abstract}

Key-words: Teacher education; Reflexive teacher.

\section{De onde falamos}

Esse texto é fruto de nossas experiências como formadores de professores que ensinam Geografia em duas instituições de ensino superior públicas. Retrata muitas perguntas a respeito do processo de 
se tornar e se formar docente.

Nasce do lugar de nossas práxis pedagógicas, como coordenador de área do subprojeto de Pedagogia inserido no Programa Institucional de Bolsa de Iniciação à Docência (PIBID) da Universidade Federal do Estado de São Paulo (UNIFESP), Campus Guarulhos, SP, e Professor responsável pela Prática de Ensino e Estágio Curricular Supervisionado do curso de Geografia da Universidade Federal do Rio Grande do Sul (UFRGS). Sua versão mais completa esta(rá) numa publicação do PIBID da UNIFESP (no prelo) intitulada 'Experiências com a formação inicial de professores: em busca do protagonismo no trabalho docente'.

Qual o sentido de formar - e/ou ser - professor para a Educação Básica? Como pensar a constituição e a construção da identidade do professor? Como potencializar o professor em formação a se sentir capaz de docenciar? São questões amplas, existenciais! Da qual não podemos fugir, pois não há como docenciar sem existenciar-se!

Vale ressaltar que, embora esses diferentes percursos se assemelhem no objetivo, suas trajetórias são dispares. Os estágios curriculares se configuram como um componente curricular obrigatório para as licenciaturas e o aluno se insere nessa senda, no geral, a partir da segunda metade do curso. 0 PIBID é um programa da CAPES, indutor de uma política pública relacionada à valorização do magistério e a melhoria da escola pública e contempla, por meio de seleção específica, os alunos da licenciatura de qualquer período mediante critérios estabelecidos por edital de seleção pública. Isso antecipa - o que consideramos salutar - o contato do aluno com a escola pública. Diferentemente da tradição, não se espera chegar na metade do curso.

Em ambos os casos, seja no PIBID, ou nos Estágios Curriculares Finais, não se trata 'apenas' de formar 'técnicos' em docenciar. Estamos falando de concepções fundantes do que consideramos o papel das instituições educativas e o papel dos seus profissionais como agentes protagonistas na formação de um aluno participativo nos ambientes de sua vida cotidiana.

Visamos contribuir na discussão que envolve o aprender a ser professor, considerando que essa formação humana só é possível quando colaborativa e coletiva tendo o local do futuro exercício profissional como referência.

\section{2 - O DESAFIO DE FUGIR DO OLHAR DE ESTRANGEIRO-COLONIZADOR: 0 PIBID E OS ESTÁGIOS DE LICENCIATURA COMO LÓCUS DA FORMAÇÃO DOS LICENCIANDOS, E DE NÓS, SEUS FORMADORES}

0 subprojeto de Pedagogia do PIBID UNIFESP (2014-2016) envolveu 25 bolsistas em três escolas da rede municipal de Guarulhos. Alunos do curso de Pedagogia. é importante realçar a constituição do grupo. Buscamos cotejar a equipe com a presença de bolsistas que estivessem em diferentes momentos do curso de graduação. Tal configuração representava um estímulo no que se refere a possibilidade de desenvolver o trabalho mais colaborativo.

Foi desafiador a entrada das bolsistas na escola. Mesmo articuladas em encontros semanais destinados a pensar coletivamente suas iniciações à docência, a inserção na instituição. Permeada de muitas tensões e choques em função das representações que tinham: a respeito da imagem do professores (provocada em larga escala pelos improvisos e falta de diretividade pedagógica); das práticas escolarizantes corriqueiras (das cópias de textos, passando pela pinturas de mapas, apologias de heróis e comemorações de datas históricas), e dos ritmos que as escola desenvolve no seu cotidiano. Ou seja, percebe-se de imediato a distância entre o que aprendemos na graduação e o que se pratica corriqueiramente nas escolas. Exemplo? 0 quase desaparecimento da voz, dos conhecimentos prévios e da experiência das crianças no planejamento da relação professor-aluno. Também o desconhecimento que nós professores temos, em geral, do público e da comunidade em que trabalhamos. Não raro nosso olhar é o de estrangeiro, de estranho, quando não de colonizador. 
As bolsistas foram estimuladas a pensar em quais perguntas poderiam lhes ajudar a pensar a própria produção social da escola. Nesse movimento surgiram indagações, por exemplo, se as bolsistas procuraram conhecer o lugar no qual a instituição está localizada? Se repararam nos diferentes ambientes constituintes da escola? Se indagarem por que a escola pinta suas paredes com desenhos estilizados, feitos por adultos? Se procuraram levantar hipóteses porque a escola costuma apresentar seus encaminhamentos pedagógicos já prontos para os alunos? Se perceberam se os professores conhecem o lugar de sua inserção profissional? Se mapearam quantos professores moram no bairro? Se procuraram saber se as crianças conhecem - de fato os lugares que constituem a escola e o bairro? E se não conhecem, quais seriam as razões? Se as famílias participam dos eventos da escola?

Exemplos de ricos episódios formativos, pois geraram discussões que sistematizaram mais claramente o entendimento acerca do local que estavam se inserindo. Bons temas para pensar a formação docente. Geram indícios cruciais para tentar ressignificar as próprias experiências docentes. Sem conhecer a comunidade em que se trabalha os equívocos podem ser enormes.

Diante das constatações iniciais relatadas pelas bolsistas de que: os professores se pautam em atividades repetitivas; as crianças parecem não ter voz nos mais diferentes lugares da escola e a instituição, representadas pelos gestores educacionais, apresenta considerações estigmatizadas a respeito das famílias, um dos primeiros movimentos foi o de indagar, diante de cada caso retratado, o que as bolsistas fariam se estivem no lugar de cada sujeito relatado? Além disso, foi evidenciado também a necessidade das próprias bolsistas olharem para o lugar onde a escola estava situada. Efetivar uma leitura que, além de reconhecer onde estavam cada um dos sujeitos, ponderar sobre a diversas relações estabelecidas entre os sujeitos e o espaço (e bairro) da escola. Ou seja, os lugares constroem significados. Marcam as pessoas que ali vivem.

Essa iniciativa constituiu um verdadeiro mapeamento. Tinha como pano de fundo uma perspectiva importante: a de pensar as territorialidades da escola e de seus sujeitos. Quem são essas crianças, professores, gestores educacionais, famílias? Tal procedimento é uma ferramenta metodológica vital na formação de professores.

Com essas preocupações enfatizamos a necessidade de se atentar para as dinâmicas que naturalizam as formas de tratamento e concepção do que é uma criança, do que é um aluno, pois isso traz impactos - não necessariamente positivos - nos processos de ensino e de aprendizagem. "Seu filho não está conseguindo acompanhar o ritmo da escola", "Essas crianças não querem aprender! Só conversam!" são julgamentos de valor que podem obstaculizar a relação professor-aluno.

Nosso princípio epistêmico é claro: ler a escola, a localização dos sujeitos e objetos, averiguar as condições materiais onde a docência se desdobra é uma preocupação central para nós. Esse encaminhamento deu visibilidade ao lugar onde se atua. 0 reconhecimento da escola por parte das bolsistas implicou uma outra forma de olhar para o local e seus sujeitos.

As bolsistas foram instigadas a identificar e examinar as práticas pedagógicas. Foram estimuladas a ler com atenção como se configurava os tempos e espaços da escola. Por meio da organização de um quadro (distribuindo os dias da semana e identificando, hora a hora, as atividades na escola) sintetizou-se quais eram as atividades envolvendo, em especial os alunos. Levantamento deveras importante. Saltou aos olhos das bolsistas o número de atividades mecanicamente desenvolvidas. Encaminhamentos como, por exemplo, cópias de trechos de livros didáticos demonstrando uma rotina bastante fragmentada com pouca articulação entre as atividades e pouco estímulo à criatividade e reflexão.

Um dos incômodos por parte das bolsistas era sobre o silêncio cobrado das crianças. Muitas das atividades buscavam deixar os alunos em constante estado de cumpridores de tarefas. Tarefeiros. Uma concepção epistemológica implícita: corpo ocupado leva à calma. Ócio como 'morada do capeta'! Havia no ar uma concepção de aluno como se fosse um 'objeto' que chega à escola desprovido de leituras e experiências de mundo.

As bolsistas colocaram em questão: por que essa invisibilidade da infância?

Todos estamos imersos numa espécie de 'aquário' que nos engloba, e, em muitos casos nos 
condiciona a sermos o que somos. 0 que nos interessa aqui, no entanto, não é o que nos condiciona e sim o espaço que temos de liberdade para propormos outras formas de ser e estar nos lugares que vivemos. Se a escola concreta se produz diariamente temos que ver as possibilidades de refazê-la. Diariamente propor.

A escola porta uma dinâmica interna não descolada do que acontece em outras escalas da sociedade. Como pensar no professor da escola da periferia sem levar em conta suas concepções de mundo? Como pensar na escola pública sem levar em conta os impactos de políticas públicas decididas geralmente distantes da realidade em que ela está inserida? Essas situações cotidianas, quando não observadas, são alguns dos exemplos que, passo a passo, descaracterizam em larga escala o sentido social da escola. Pensar sobre esses acontecimentos considerando os diferentes lugares onde acontecem, e a maneira como os sujeitos envolvidos constroem suas alteridades (e identidades) tem nos permitido buscar alternativas de ação.

Repetições que saltaram aos olhos das bolsistas: cópias de trechos de livros didáticos, sessões de vídeos nitidamente aleatórios, infindáveis listas de exercícios - de contagem, soma, escrita do nome do amigo, pesquisas sobre lugares do mundo e personalidades sem contextualização, assim como a memorização exaustiva de nomes de órgãos do corpo humano e de plantas, ... alunos não fazendo perguntas ... alunos fazendo um barulho ensurdecedor. Onde querem chegar os professores com essa ocupação mecânica dos discentes? Construir alunos 'comportados'? Ou cidadãos dóceis?

Isso nos ajuda a entender porque temos tanta dificuldade em transformar as rotinas da escola. Há determinações de várias ordens (sociais, econômicas, políticas, históricas, geográficas, éticas, psicológicas, etc.) que impactam a escola. Soma-se a isso também o fato de que nós adultos fomos moldados, desde muito pequenos, por uma instituição - a escola - que é secular. Mudar um adulto - e todos nós professores somos adultos - é muito trabalhoso. E o resultado, incerto.

Embora essa etapa do ensino fundamental apresente a configuração de um professor que é polivalente, as áreas do conhecimento se traduziam em disciplinas tal como nos anos finais do Ensino Fundamental. Havia claramente uma ênfase na Língua Portuguesa e na Matemática. Em momentos aleatórios havia alguma inserção de História e Geografia. Todas vistas de forma estanque. Muitas vezes, o tema estava sendo desenvolvido sem que seus vínculos e razões estivessem claros. Ou seja, os objetivos do que se ensinava não eram explicitados para os alunos. Talvez estivessem pouco claros para os próprios docentes. Percebemos a dificuldade em fazer relações entre os diferentes assuntos e disciplinas escolares. A boa intenção da interdisciplinaridade é muito propalada, mas de difícil execução .

Tal constatação desencadeou indagações: qual o currículo que estamos propondo, seja aos nossos alunos de Graduação, seja aos da Educação Básica? Quais os sentidos para o conhecimento trabalhado na escola? 0 quanto professores e gestores tem de autonomia para fazerem de outras maneiras a escola 'funcionar'? Já dissemos: o educador pode muito pouco, mas este pouco não é nada desprezível (Kaercher, 2014).

Enfatizar a necessidade de considerarmos as experiências dos sujeitos nos convida a pensar o outro num exercício de empatia, de pensar-se na pele do outro. É mais difícil que o que normalmente fazemos: simpatizamos ou antipatizamos com os outros.

Em muitos casos, a escola se coloca estabelecendo um padrão único no que tange às formulações do conhecimento. 0 conhecimento é visto como uma situação que será atingida no final do ato de estudar ("esses alunos estão se preparando para o futuro..."). Outras leituras de mundo - feitas pelos alunos - muitas vezes não são consideradas. Ou se são, são consideradas "erradas" ou "simplórias".

Reforçar a compreensão de que o conhecimento se constrói nas relações cotidianas entre as pessoas, ou seja, não é somente na escola que se 'produz conhecimento'. Isso permite a construção de discursos e ações pensando em quem somos, onde estamos e o que queremos transformar e propor. Trata-se de propormos e construirmos com nossos alunos o 'pensamento ampliado', isto é, "a curiosidade pelo outro, essa vontade constante de ampliar seus horizontes" (Ferry, p. 166, 2009). Reconhecer a beleza e o valor do outro, 
O PIBID é uma política pública poderosa porquê: a) estreita a relação escola e universidade pública, b) permite a imersão do alunos na instituição escolar antes da segunda metade do curso, e, c) estimula o retorno das descobertas no dia a dia da escola para o ambiente acadêmico e vice versa. Sem dúvida, o PIBID é alvissareiro no que diz respeito à formação de professores. É um fato novo na formação de docentes. Os efeitos positivos no desenvolvimento intelectual dos pibidianos é inegável.

Para encaminhar o texto gostaríamos de deixar algumas características observadas nas escolas para motivarem reflexões e possíveis ações.

Nas aulas de Geografia observadas pelos estagiários também são comuns atividades de cópia, seja do quadro, seja do livro didático. A ocupação mecânica dos alunos. Uma estratégia de lento escoar da aula. Não estamos julgando. A cópia de umas poucas frases pode levar um tempo incrível e com boa chance de ficar só na cópia, ou seja, não se pensa sobre o que está sendo copiado. Podemos usar melhor este instrumento, com certeza.

Outro paralelo: a dificuldade - ou desinteresse - dos educadores já experientes em se interessarem pelo universo simbólico dos alunos e da própria localidade onde atuam. Há uma dificuldade, que é epistemológica, de se ouvir o outro, o aluno. Não é que haja muito barulho, desatenção. Isso até pode ser consequência da falta de diálogo entre os sujeitos envolvidos na relação pedagógica. Por não haver uma troca interessada de conhecimentos prévios que os alunos trazem, o educador corre o risco de (ainda) manter a postura de falar para os alunos, como se fossem receptáculos esvaziados de saber e opiniões. 0 exercício da escuta qualificada e da empatia são ainda grandes objetivos a perseguirmos para dar um maior sentido a escolarização de tantos jovens. Torná-los sujeitos na prática e não apenas nos Planos Políticos Pedagógicos, onde o mantra da educação 'crítica' e 'conscientizadora' é amiúde repetido. 0 esvaziamento da importância da escola e da própria profissão docente requer algumas mudanças dos professores: propor temas escolares que dialoguem com os conhecimentos prévios dos alunos é uma forma de dar mais força à escola e a nós envolvidos, alunos e professores.

Sem ter a solução para esse descompasso que afasta o aluno de nos ouvir com intenção - sim, sabemos, os motivos são vários e não queremos culpabilizar o professor - gostaríamos de sugerir o permanente exercício de fazermos perguntas abertas (cujas respostas não sabemos de antemão) aos alunos. Com a intenção de diminuirmos a invisibilidade deste. Junto a isso, reafirmar a crença na capacidade cognitiva e no interesse do aluno. Ele sabe ou, se não sabe, quer saber. Isso é uma aposta no aluno. Eles percebem, com facilidade, quais professores apostam neles, acreditam que eles são capazes de coisas belas. Percebem os professores que estão interessados em compartilhar com eles 'coisas legais'. Isso não é apenas uma crença ingênua dos autores. Não, é corroborado por várias pesquisas que, ao ouvir os alunos, atestam a importância que eles dão tanto à escola como aos professores que se interessam por eles. Não somos milagreiros, mas propor questões e temas ligados a vida cotidiana dos alunos pode fazê-los ouvirem nossas aulas com mais interesse.

Um professor sem objetivos claros tende a se dispersar em vários assuntos, e, por conseguinte, dispersar o aluno. Aqui falamos não apenas - o que já não seria pouco - dos objetivos pedagógicos em ensinar este ou aquele conteúdo, mas pensar o próprio sentido existencial e ontológico que a escola tem para nós, professores, e, claro, para eles. Existencial porque requer o já citado exercício da empatia. Pensar-se na pele do outro.

\section{3 - CONCLUINDO: A ESCOLA GANHA MAIS COR E VIDA QUANDO DESENVOLVE A EMPATIA E A AUTORIA}

Há exemplos de muitas coisas belas que professores e alunos fazem nas salas de aula dando sentido a esse duro ofício. Exemplos desanimadores também não faltariam, mas mais do que simpatia ou antipatia a esta ou aquela posição ou atitude dos professores e alunos, queremos enfatizar que as 'soluções' para as dificuldades que as escolas enfrentam não passam necessariamente por soluções 'técnicas', por dicas metodológicas ou mais equipamentos. Tudo isso é válido, preciso, útil. Só um 
lunático deixaria de lado as inúmeras dificuldades que as escolas públicas que tanto afetam a qualidade e o ânimo dos educadores e educandos. Pensar políticas públicas de atração da juventude à docência é um problema a ser enfrentado com urgência e recursos. 0 risco de apagão no interesse pela docência é real.

Um desafio que temos como formadores é o de ampliar a identificação e a compreensão dos futuros docentes no entendimento da escola pública.

As experiências formativas (inicial e continuada) de professores aqui expostas nos fornecem algumas pistas para concluir acerca da importância de colocarmos o quanto antes os estudantes de licenciatura em contato com as escolas de Educação Básica.

Quanto antes estes estudantes puderem conhecer o mundo cotidiano real das escolas melhor serão capacitados para o exercício profissional. Claro, não advogamos um empirismo rasteiro onde se crê que basta a 'prática' para a formação inicial. Implícito está aqui a ideia de uma formação assessorada por professores, seja os da universidade, seja os das escolas que recebem nossos alunos. Nada mais prático que uma teoria testada nos embates do cotidiano. Implícito está também o caminho do esforço individual do estudante, pois ainda que esteja na prática e, ainda que esteja assessorado por profissionais experientes, pouca serventia terá isso se o discente não for dedicado ao seu aprimoramento intelectual. E isso requer estudo e isso requer disciplina individual.

Outra possível 'conclusão' é perceber que a carreira docente no Brasil é de pouca atratividade. Nesse sentido destacamos a importância de programas como o PIBID no estímulo a formação de bons quadros docentes. É inegável o nosso temor de um crescente/permanente desestímulo para as novas gerações optarem por 'opção' (sic) por esta carreira e não, como, muitas vezes ocorre, fazer a escolha pelas licenciaturas por falta de 'melhores' oportunidades no mercado de trabalho.

Para atenuar ou reverter a pouca atratividade que a carreira docente apresenta faz-se necessário a permanência e/ou a expansão de políticas públicas de fortalecimento da atratividade das licenciaturas: educação de boa qualidade não custa pouco, não sai barato, mas não deve ser vista como 'gasto' e sim como 'investimento'.

Não podemos deixar a formação de professores apenas a vontade pessoal, a crença que é o 'mercado' que vai atrair jovens. É uma questão de Estado, portanto, requer uma política pública contínua de fomento a formação de novos educadores.

Todo educador é um crente, aliás, tem que sê-lo, senão sucumbe rápido na profissão. Tem que crer na profissão (como ser professor sem querê-lo?), tem que crer na sua área de conhecimento (como lecionar Geografia se não cremos que este seja um conhecimento atrativo e relacionada a um sentido social?), tem que crer no aluno (como vou me motivar a ensinar se os meus alunos são por mim considerados inaptos ou relapsos?).

A aposta e a ação é que a educação pública atenda com qualidade seu público, no geral, pessoas de condições sociais mais humildes que tem e veem ainda na escola, a chance de crer num futuro mais promissor. Isso já não é mais uma aposta nossa: é um programa civilizatório. Uma sociedade mais democrática e inclusiva passa pelo fortalecimento da escola pública, pois ali estão $80 \%$ dos nossos estudantes. 0 livre mercado pouco se importa com estes que não podem pagar, logo, diminuir o Estado é apostar no abandono dos já excluídos. Precisamos fortalecer a economia? Claro que sim, mas discutir que sociedade temos e queremos é um processo civilizatório que escola alguma pode prescindir.

\section{Referências}

CASTROGIOVANNI, Antonio C. et al (orgs). Movimentos para ensinar geografia - oscilações. Porto Alegre: Editora Letra1, 2016.

FERRY, Luc. A sabedoria dos mitos gregos. Aprender a viver II. Rio de Janeiro: Objetiva, 2009. 
HARARI, Yuval N. Sapiens: uma breve história da humanidade. Porto Alegre: L\&PM, 2015.

HARARI, Yuval N. Homo Deus. São Paulo: Companhia das Letras, 2016.

KAERCHER, Nestor André. Se a Geografia é um pastel de vento o gato come a Geografia Crítica. Porto Alegre: Evangraf, 2014.

KAERCHER, Nestor André. De astronautas e extraterrestres; de partos e gregos ... todos nós entendemos um pouco. Em busca da Geografia do já é! (p. 151 - 169). In: MARTINS, Rosa E. M. W. et al (Orgs.). Ensino de Geografia no contemporâneo: experiências e desafios. Santa Cruz do Sul (RS): EDUNISC, 2014.

PORTUGAL, Jussara. F.; CHAIGAR, Vânia A. Martins (orgs). Educação Geográfica: memórias, histórias de vida e narrativas docentes. Salvador: EDUFBA, 2015.

PORTUGAL, Jussara. F. et al (orgs). Formação e docência em Geografia: narrativas, saberes e práticas. Salvador: EDUFBA, 2016. 